\title{
Chocano, traductor
}

\section{Un aspecto y un libro ignorados del gran poeta}

\author{
por Luis Alberto Sánchez
}

Entre 1908 y 1913, José Santos Chocano, a la sazón al borde de los cuarenta, se enfrentaba a los más áspero de su destino. Su aventura de España habíale traído desagradables y hasta ruinosas consecuencias. Lo testimoniaba la violenta forma como hubo de abandonar La Habana y pasar a Nueva Orleans, con nombre supuesto. Menos mal que para un tan intrépido corazón nada sería nunca derrota definitiva, sino acicate. Y así, después de una breve y jugosa permanencia en Puerto Rico, y de un centelleante idilio en Guatemala, Chocanoeselencaró de nuevo, sin titubeos, a su nueva vida.

En el paréntesis era preciso trabajar, producir. Chocano fue siempre un laborioso infatigable. A sus ilusiones literarias se mezclaba un agudo sentido práctico, del que fluían innumerables ensueños de otro juez; el utilitario y financiero. Claro está que, a raíz de la multitud de rumores lanzados irresponsablemente a todo viento, como consecuencia de su intempestiva salida de España y el abandono de su carrera diplomática, era muy difícil que pudiera encabezar una de aquellas empresas gigantescas, dignas de un Carnegie o un Morgan... ( nos habituaría después el esforzado paladín de verso continental.

Pues mientras se preparaba el ambiente para aquellas ciclópeas hazañas, hubo de conformarse a lo menos clamoroso y próspero, y hacerse de pequeñas tareas cotidianas, suficientes para su sustento. Las tareas de periodista en "El Fígaro" y "El Diario de la Marina" de la Habana eran mucho, pero no todo. Y como ya 
había entablado relaciones con aquella astuta "protectora" de los poetas latinoamericanos, la "Librería de la Viuda de Ch. Bouret", editora de "Los Cantos del Pacífico" y "Alma América", Chocano le confió el proyecto de publicar un tomo de poemas del ilustre brasileño Da Fontaura Xavier, entonces en la carrera diplomática en que conociera a su ya excolega José Santos Chocano.

Fue una labor árdua, como la de todo traductor, pero aún más, porque Chocano quiso mantener el tono y ritmo del original brasileño. De donde, aunque hay mucho de personal y hasta algunas añadiduras inevitables, la traslación es fiel, y si, a menudo, falta poesía, casi siempre sobra fidelidad.

El volumen que tenemos a la vista, y que constituye otra rareza bibliográfica, análoga a la de "Puerto Rico lírico" editado en San Juan P/R. también en 1914 tiene la siguiente portadilla:

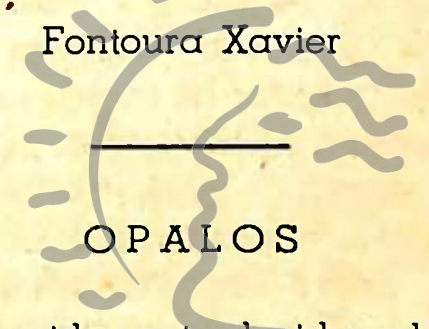

Poesías escogidas y traducidas al español

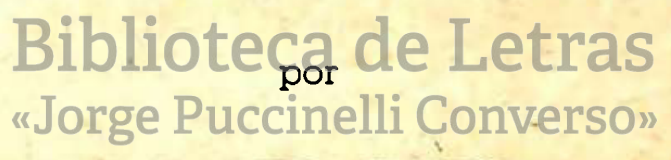

JOSE SANTOS CHOCANO

(una viñeta de letras)

Librería de la Vda. de Ch. Bouret.

París

México

23, rue Visconti, $23 / 45$ Avenida Cinco de Mayo, 45

1914

Como la Librería Bouret no siempre fue muy exacta en mantener o cambiar la fecha de sus reediciones, se hace dudoso saber st, realmente, se trata de la primera edición, aunque todo lo hace pensar así. Debemos, en consecuencia, admitir la fecha indicada 
como auténtica, ya que calza además con la época en que Chocano se hallaba totalmente entregado a la tarea de "vivir de su pluma".

No podía faltar desde luego, un prólogo muy "chocanero". El énfasis del "cantor de América" llegaba en esos momentos a su punto más alto. Ebrio de egolatría se presenta más bien como Mesías que como traductor. Las citas de Whitman, entonces, o sea en 1912-14, ratificaban su adhesión temperamental y vocaciona a la poesía profética del Gran Viejo. Walt Whitman, no lo olvidemos, fue la más apasionada de las Conquistas de los Modernistas latinoamericanos. En Francia no se le conocería prácticamente, sino hasta que León Bazalgette le tradujo en 1916, en la pulcra edición del "Mercure de France" (2 vols.), lo cual ocurre tres lustros después de que el autor de "Leaves of Grass" ya circulaba en esta parte del mundo. Armando Vasseur le había vertido al Castellano desde 1912. Darío lo saludaba en uno de los "Medallones" de la segunda edición de Azul, hacia 1891. Lugones lo exalta en uno de los cantos de "Las Montañas del oro" (1897). Pero, desde antes, José Martí, en Nueva York, nos revela la magnificencia y el poder del extraordinario bardo. Tampoco emitiría su elogio al respecto, desde 1892, Enrique Gómez Carrillo. La devoción de Chocano a Walt Whitman no era, pues, particular ni restricta, sino fruto de la educación y pesición de los escritores de su tiempo.

He aquí lo que dice Chocano en el Prólogo a su traducción de Da Fontoura Xavier :

"Cuando Rubén Darío enarboló, como epígrafe de sus exámetros (sic. - LAS) al Aguila norteamericana, el primer verso del canto a la misma que, en años anteriores, diera a los públicos latinos el poeta brasilero Da Fontourra Xavier, no podían imaginarse que, andando yo y el tiempo en tierras de Centroamérica, vendría mi diestra a estrechar la del noble compañero.- La representación Diplomática de su gran patria en las repúblicas ístmicas, trajo a Fontoura Xavier a mi conocimiento personal: su figura breve y nerviosa, sus ojos imperativos que confirman cuanto dicen sus labios, hácenle un tipo recalcitrante de intelectual latino, que a poco de platicar se anima y pone en su mano de amigo, un calor de sinceridad que se le sale del corazón". 
Si examináramos con despacio el párrafo transcrito, hallaríamos en él varios importantes elementos para establecer: 1) la imprenta de México en el habla de Chocano, o, mejor dicho, la de Guatemala, a la de México a través de Guatemala ("platicar"); 2) la irrestañable vanidad ("andando yo y el tiempo"... "vendría mi diestra a estrechar"... "trajo a mi conocimiento personal"...); 3) el énfasis retórico de una presa algo acartonada o pétrea, que abusa del proclítico y de la perífrasis como en parlamento de teatro antiguo. Estas tres notas no son aisladas. Tampoco esporádicas. Se repetirán hasta la saciedad. Agreguemos este párrafo sentencioso, eco de algunos versos de entonces, con más ruido que sonido:

"Tal me complace reconocer que Da Fontoura Xavier tiene bien puesto su corazón de poeta y bien firme su cabeza de hombre".

Por primera vez, acaso, se advierte a Chocano interesado directamente en la poesía francesa de su tiempo. Y aunque ceda a su apotegmática tendencia, más de orador que de poeta, como cuando dice: "El poeta ha de ser múltiple como hombre: Dante es filólogo; Goethe, naturalista; Hugo, político; Camoens, soldado; Espronceda, financista", a renglón seguido alụde a Baudelaire (E el gato negro de Baudelaire", "al diabolismo de Barbey d' Aurevilly", al, "atildamiento de Banville", y al "cuervo del yanqui maravilloso" (Poe). JDos epítetosiresudan conformismo con el ambiente. Ninguna revelación. Si acaso, la duda de que no los tenía enteramente leídos a "Las Diabólicas", Banville fue mucho más que "atildado", el creador o recreador del versolibrismo, y en la imaginería de Poe y Baudelaire hay mucho, muchísimo más que "gatos negros" y "cuervos". Lo dicho parece utilería literaria, sin sombra de pasión poética. Chocano se halla en ese momento asomado a su personalidad. Como desde un balcón, se descuelga desde su orgullo hacia el mundo externo. Detrás de él, muro improvisado, puertas y ventanas le aislan del calor de la casa, de su casa, de su vida interior.

En estas condiciones, la elección de Da Fontoura Xavier como blanco de sus traducciones se entiende muy bien. Y la forma de trasladarlo, que él confiesa como un intento de "seguir en mis traducciones paralelamente la letra y el espíritu de cada poesía de Fontoura Xaxier". Difícil empeño. Si hay poesía impermea- 
ble al énfasis, es la moderna poesía brasileña. Veamos esto a la luz del libro que tenemos a mano y de otras experiencias.

El escritor brasileño (no brasilero, como dice Chocano; que romeros eran todos los que iban a Roma, pero romanos sólo los hijos de Roma), tiene una curiosa y seductora dualidad: su propensión al lirismo, a veces algo enfático, y su inevitable tendencia a la ironía que suaviza el énfasis, a cierto suave escepticismo, deliciosa forma de la cortesía. Sin buscar muchos ejemplos, veámoslo hasta en el dolorido y romántico Castro Alves y, claro, en el incomparable Machado de Assis, y en los marmóreos sonetos de Olave Bilac, donde la sonrisa no litigia con la solemnidad. Si venimos a nuestros tiempos, ¿quedaría algo de la poesía de Manoel Bandeira, Drumont de Andrade, si los despojáramos del "humour" con que atemperan de sarcarsmos sus dolencias y dolores?

Chocano careció del sentido del "humour". Era hombre de una vertiente literaria. Perentorio, delamatorio, solemne, majestuoso, imperia vaticinante. De ahí que, aparentemente acierte, cuando traduce poemas de Fontoura Xavier, donde este se muestra más parnasiano-francés que humano brasileño. $Y$, sin embargo, ahí mismo se echa a ver la manía solemne del traductor. "El Aguila Calva", "La Muerte de Geraldo de Nerval", ponen a Chocano en contacto con temas y tonos que se le antojan casi propios. Error vitando. Tan cierto que hay versos de un prosaismo intolerable, que no suenan igual en portugués, porque el valor de las palabras es distinto en estecidiomá queven el nuestro. Pongamos por ejemplo:

París despertó; y pudo gozar del espectáculo. El cuervo desprendióse de la cabeza inerte... París se rió mucho del miembro del "Cenáculo"; rió, rió, y se estuvo riendo de la muerte... (p. 39).

En "Spleen", que es de lo mejor vertido, Chocano, obsesionado por la pasión de la rima, cae en las licencias entonces y hoy intolerables, aunque las salve el doble impulso del autor y del trasladante:

Tengo un fantasma secreto

dentro de mi corazón......

Vestido a veces de Hamlete se va a pasear al panteón. 
Convengamos: aparte de lo innecesario de esa rima de "Hamlete" con "secreto", hay concesiones coloquiales insufribles como ese "se va a pasear al Panteón", que pudo abviarse con un severo "pasea por el panteón", análogo, a aquella otra terrible concesión: "París se rió mucho del miembro del Cenáculo" donde uno, se extraña de la total ausencia de poesía y gracia. Menos mal que "En los funerales de un poeta", "El náufrago" y "Musa libre", el traductor alcanza mejores acentos, hasta confundirse con su traducido.

Las 167 páginas del volumen, de que se hicieron 6 ejemplares en papel Japón, reunen 47 composiciones. Los epigramas finales, tan característicos de la poesía brasileña, hecha de saudades portugesas, licencia y concresión francesas, luminosidad de cielo americano, sensualidad africana y algo de pulcritud y sintetismo asiáticos, son los menos apropiados para un traductor de la calidad de Chocano. Sin embargo, por si solos denuncian la ironía de Fontoura Xavier :

Bluft

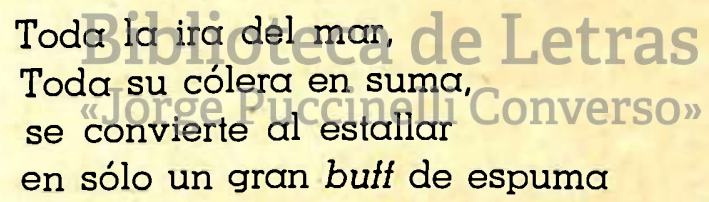

Convengamos que este tono era el menos apropiado para un hombre como Chocano. Si se lanzó a la traducción fue por dos razones evidentes; una, su amistad personal y su devoción a Fontoura Xavier, entonces ya Ministro del Brasil en Londres, después de haberlo sido en Centroamérica; y dos, la urgencia de ganar su sustento por la única vía entonces a su alcance : la literatura. Al mismo tiempo, sirve este pequeño episodio de la complicada y resuelta vida chocanesca para relievar sus consonancias y disonancias con los demás miembros del movimiento (si acaso) modernista, la solemnidad castellana de su inspiración y forma, tan lejos de la sutileza y matices de la poesía francesa. Lo cual delimita y define, mejor que nada, la órbita poética de Chocano en ese tiempo. 